\title{
CONF-970907--1
}

\section{Determination of Actinide Isotope Ratios Using Glow Discharge Optogalvanic Spectroscopy}

\author{
J. P. Young, R. W. Shaw, C. M. Barshick, and J. M. Ramsey \\ Chemical \& Analytical Sciences Division \\ Oak Ridge National Laboratory \\ P.O. Box 2008 \\ Oak Ridge, TN 37831-6142 USA

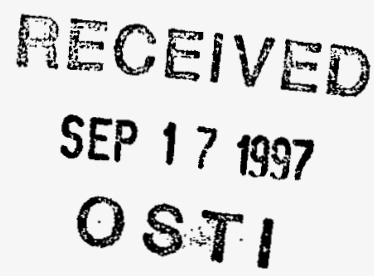

\section{ABSTRACT}

Diode-laser excited optogalvanic spectroscopy (OGS) of a glow discharge has been utilized to measure U-235/U-235 + U-238 isotope ratios. This "optical mass spectrometric" measurement has been demonstrated for a number of samples including uranium oxide, fluoride, and metal. Various diode-laser accessible atomic transitions in the 775 to $835 \mathrm{~nm}$ region have been evaluated; these transitions were chosen by considering OGS sensitivity and isotope shift. Using the $831.84 \mathrm{~nm}$ uranium line, for example, it was possible to measure the U-235/U-235 + U-238 isotope ratio (0.0026) of depleted uranium samples. A prototypical field instrument to make these measurements has been assembled and demonstrated. A U-236 spectral line was identified in a sample of enriched uranium, and an abundance sensitivity was measured.

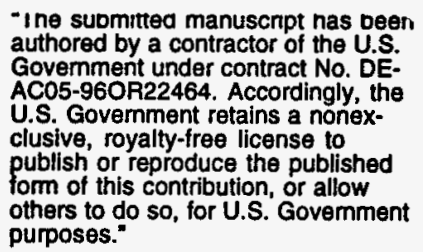

Research sponsored by Office of Research and Development, U.S. Department of Energy, under Contract DE-AC05-96OR22464 with Oak Ridge National Laboratory, managed by Lockheed Martin Energy Research Corporation.

DISTRIOUTION OF THS DOCURAENT \& UUMMTED
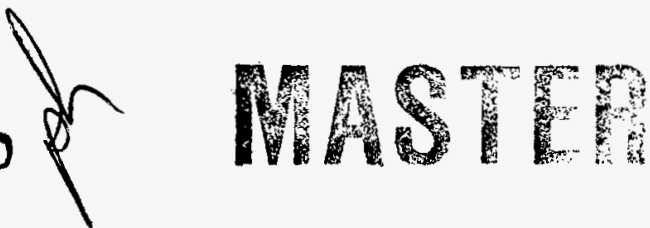
DTIC QUALTYY INBPEUTRD 8 


\section{DISCLAIMER}

This report was prepared as an account of work sponsored by an agency of the United States Government. Neither the United States Government nor any agency thereof, nor any of their employees, make any warranty, express or implied, or assumes any legal liability or responsibility for the accuracy, completeness, or usefulness of any information, apparatus, product, or process disclosed, or represents that its use would not infringe privately owned rights. Reference herein to any specific commercial product, process, or service by trade name, trademark, manufacturer, or otherwise does not necessarily constitute or imply its endorsement, recommendation, or favoring by the United States Government or any agency thereof. The views and opinions of authors expressed herein do not necessarily state or reflect those of the United States Government or any agency thereof. 


\section{INTRODUCTION}

Measuring isotope ratios is generally a time consuming, analytical procedure that requires expensive, cumbersome laboratory equipment to obtain the best possible precision $( \pm 0.1 \%)$ and accuracy. Particularly for lanthanides and actinides, there is a need for a rapid, simple mass analysis that might sacrifice some precision and sensitivity for speed. We have exploited the simplicity of diode laser excited optogalvanic spectroscopy (OGS) of a glow discharge (GD) to develop a simple "optical mass spectrometer." This instrument is field portable and can analyze solid samples. For the case of uranium it can measure U-235/U-235 + U-238 isotope ratios as low as $0.3 \%$ with $\pm 15 \%$ RSD precision. For enriched $U$ samples the precision is better, $\sim \pm 3 \%$ RSD. This technique is simple and inexpensive relative to conventional mass spectral analysis, and it provides an isotope screening analysis of lanthanides or actinides with provisions for further analysis of the same sample if warranted.

\section{EXPERIMENTAL}

The apparatus for carrying out these studies has been described. ${ }^{1,2}$ Essentially a solid sample, 150 $\mathrm{mg}$, was mixed with $150 \mathrm{mg}$ of a 50-50 weight \% mixture of powdered Ta and $\mathrm{Ag}$. This mixture was pressed into a tube-shaped cylindrical pellet, $5 \mathrm{~mm}$ O.D., $2.5 \mathrm{~mm}$ thick, with a $2.4 \mathrm{~mm}$ hole in the center. The pressed sample composite was made using either a standard commercial press or a stainless steel cylinder and two opposing 3/4" - 16 machine bolts. The prepared sample constituted the cathode in a GD cell; the anode was the cell wall. The discharge was maintained at $600 \mathrm{~V}$ in $1050 \mathrm{~Pa} \mathrm{Ar}$ gas flowing through the cell at $3 \mathrm{~cm}^{3} \mathrm{STP} / \mathrm{min}$. Light from a tunable semiconductor diode laser, 10 to $40 \mathrm{~mW}$, was passed through windows in the GD cell and through the center opening in the sample cathode. As the wavelength of the diode laser was tuned across isotope transitions of uranium in the sample plasma, an OGS signal was produced which was proportional to the concentration of that isotope in the discharge. A prototype for a field instrument was developed and will be described in the next section.

\section{RESULTS}

We have quantitatively investigated this OGS-GD technique for several lanthanides but have concentrated on measuring U-235/U-235 + U-238 isotope ratios. There are a number of diode laser accessible atomic uranium transitions that could be utilized for this GD-OGS technique. ${ }^{3}$ One looks for sufficient intensity of the OGS signal and reasonable isotope shift in choosing an 
analytical line. Several transitions that were evaluated are given in Table I. A typical averaged OGS spectral scan for the uranium transition at $776.2 \mathrm{~nm}$ is given in Figure 1; the sample was depleted uranium metal ( $0.3 \% \mathrm{U}-235)$. A generalized calibration plot for various uranium isotope ratio measurements using the $776.2 \mathrm{~nm}$ transition is shown in Figure 2. As can be seen, the technique works equally well for uranium metal, uranium oxide, or uranium fluoride; since it is demonstrated to work for these compounds, it would also be expected to be applicable to any uranium compound of less thermodynamic stability. Note that the precision is obviously poorer as the U-235 content decreases, but the measurement is quite adequate for identifying depleted, natural or enriched uranium. We have not evaluated the technique for other actinides, but it would be expected to be equally applicable to isotope ratio measurements for any f-element sample for which the isotope shift is adequate. In reality it would be applicable to any inorganic sample for which the analyte atom has an accessible optical transition within the range of a tunable laser.

A prototype of a field GD-OGS instrument has been developed specifically for U-235/U-235 + U-238 isotope ratio measurements. The details of this instrument are given in a technical report. 4 The configuration of the components of the instrument is shown in Figure 3. The GD cell is shown in the upper left edge of the layout. It has extended window tubes to minimize sample condensation. For field operation the pressure of the GD cell and the gas flow rate were set by using capillary restrictions. The key to operation of this instrument is wavelength control and scan. The wavelength of an optically-isolated diode laser was controlled using a notebook computer. The computer was programmed to scan the diode laser wavelength by changing its drive current in a sawtooth fashion across the isotope shift region of a particular uranium transition. Course wavelength information was received from measurement of the transmission through an interference filter; fine wavelength information was determined using a unique wavelength measuring application 5 of a liquid crystal tunable filter combined with a balanced receiver. The resulting spectrum was displayed and stored. The various photodiodes (P-diodes) shown in the figure collect the optical information from the course and fine wavelength monitors to be utilized in the computer diagnostic software. A commercial uranium hollow cathode lamp was also included in the system, to be used as a reference sample for procedural verification. In a demonstration of the prototype instrument, a GD-OGS measurement of a U-200 NIST uranium oxide sample (20.19\% U-235) yielded a value of $19 \%$ U-235. The uranium transition used for this demonstration was at $831.8 \mathrm{~nm}$.

In other GD-OGS spectral studies of the U-200 sample at $831.8 \mathrm{~nm}$ with our laboratory apparatus, it is of note that we observed a signal from U-236 in enhanced presentations of the spectral range between U-235 and U-238; an example of these spectral results is shown in Figure 4. This sample 
of $20 \%$ enriched U-235 contains $0.1 \%$ U-234 and $0.2 \%$ U-236. Based on the U-234 and U-238 isotope shift information for the uranium levels involved in the $831.8 \mathrm{~nm}$ transition ${ }^{3}$, the signal seen in the figure near $-5.7 \mathrm{GHz}$ can be attributed to $\mathrm{U}-236$. Comparing the area measurements of the U-235 and U-236 peaks in this sample, a U-236 abundance of $0.25 \%$ is obtained; the NIST certified value for $\mathrm{U}-236$ is $0.2116 \%$ for this standard.

\section{REFERENCES}

1. C. M. Barshick, R. W. Shaw, J. P. Young, and J. M. Ramsey, Analytical Chemistry 66, 4154 (1994).

2. C. M. Barshick, R. W. Shaw, J. P. Young, and J. M. Ramsey, Analytical Chemistry 67, 3814 (1995).

3. R. Engleman, Jr. And B. A. Palmer, J. Opt. Soc. Am. 70, 308-317 (1980).

4. R. W. Shaw, J. P. Young, C. M. Barshick, and J. M. Ramsey, "Glow Discharge Instrument for Uranium Isotopic Analysis: U.S. D.O.E. Final Report, K/NSP-480, Lockheed Martin Energy Systems, Y-12 Plant, June 1997.

5. Unpublished Studies, R. W. Shaw. 
Table 1. Relative strengths and isotope shifts of various uranium transitions investigated

\begin{tabular}{|c|c|c|c|}
\hline $\begin{array}{c}\text { Wavelength } \\
\text { (nm) }\end{array}$ & Transition & $\begin{array}{c}\text { Relative } \\
\text { optogalvanic } \\
\text { intensity }\end{array}$ & $\begin{array}{c}\text { Isotope } \\
\text { shift3 } \\
\text { (GHz) }\end{array}$ \\
\hline 835.71 & $3868-15831 \mathrm{~cm}^{-1}$ & 0.16 & 11.6 \\
\hline 831.84 & $4275-16294 \mathrm{~cm}^{-1}$ & 0.26 & 10.1 \\
\hline 822.31 & $6249-18406 \mathrm{~cm}^{-1}$ & 0.19 & 10.4 \\
\hline 791.88 & $4275-16900 \mathrm{~cm}^{-1}$ & 0.16 & -9.2 \\
\hline 790.04 & $4275-16929 \mathrm{~cm}^{-1}$ & 0.17 & 0.6 \\
\hline 788.19 & $6249-18932 \mathrm{~cm}^{-1}$ & 0.27 & 9.5 \\
\hline 778.42 & $620-13463 \mathrm{~cm}^{-1}$ & 1.00 & 3.0 \\
\hline 776.19 & $7005-19885 \mathrm{~cm}^{-1}$ & 0.10 & -12.6 \\
\hline
\end{tabular}




\section{FIGURE CAPTIONS}

Figure 1. Average optogalvanic signal for three spectral scans near $776 \mathrm{~nm}$ for a depleted $(0.3 \%$ U-235) uranium metal/silver sample cathode. The detection gain was increased tenfold at the indicated position.

Figure 2. Measured U-235/U-235 + U-238 ratio versus reference value (certified value or thermal ionization mass spectrometric measurement) for several uranium compounds.

Figure 3. Configuration of the components for the field prototype GD-OGS instrument for measuring uranium isotope ratios.

Figure 4. Enhanced GD-OGS spectrum of an enriched uranium oxide sample (20\% U-235) showing signal for $0.2 \% \mathrm{U}-236$. 


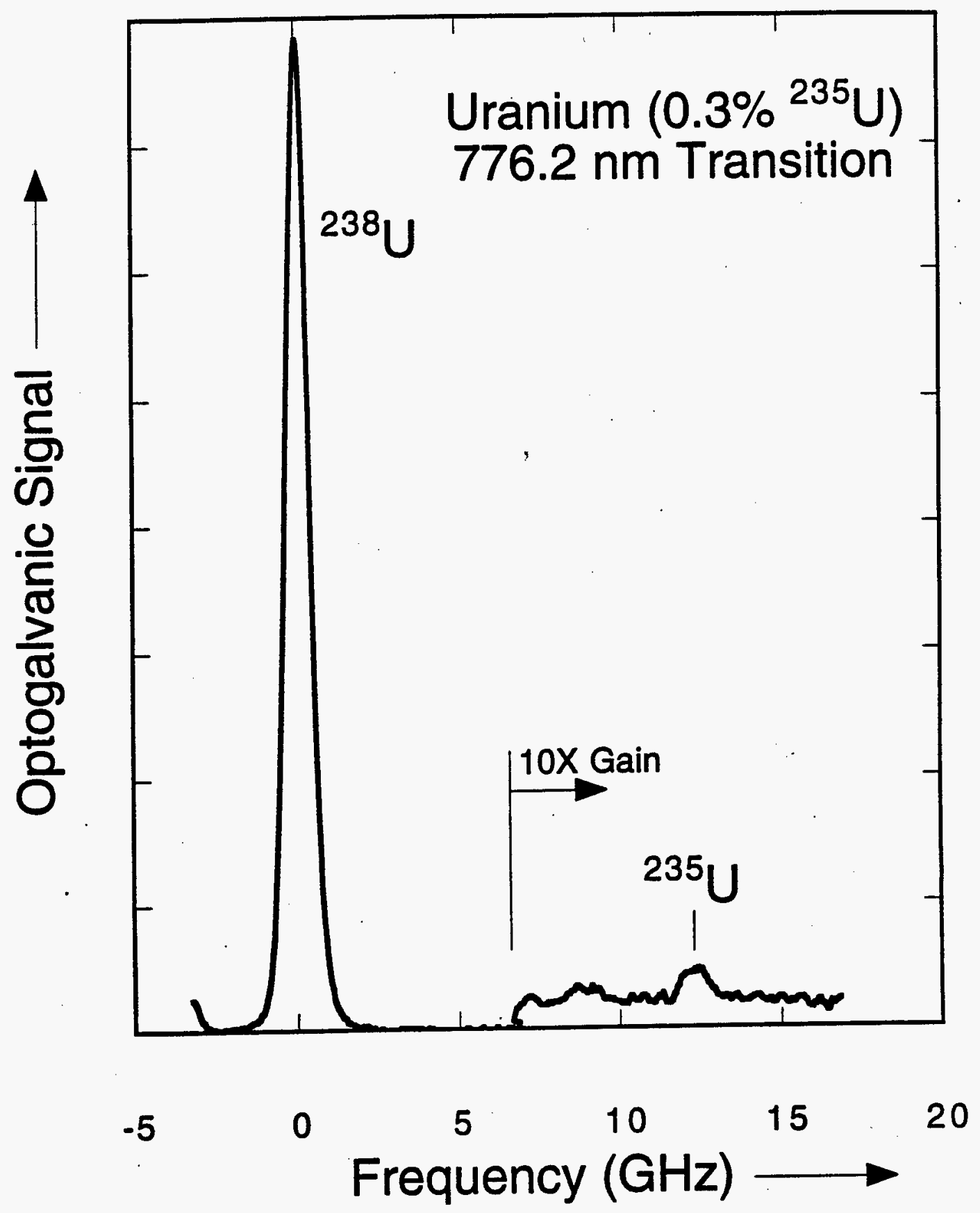




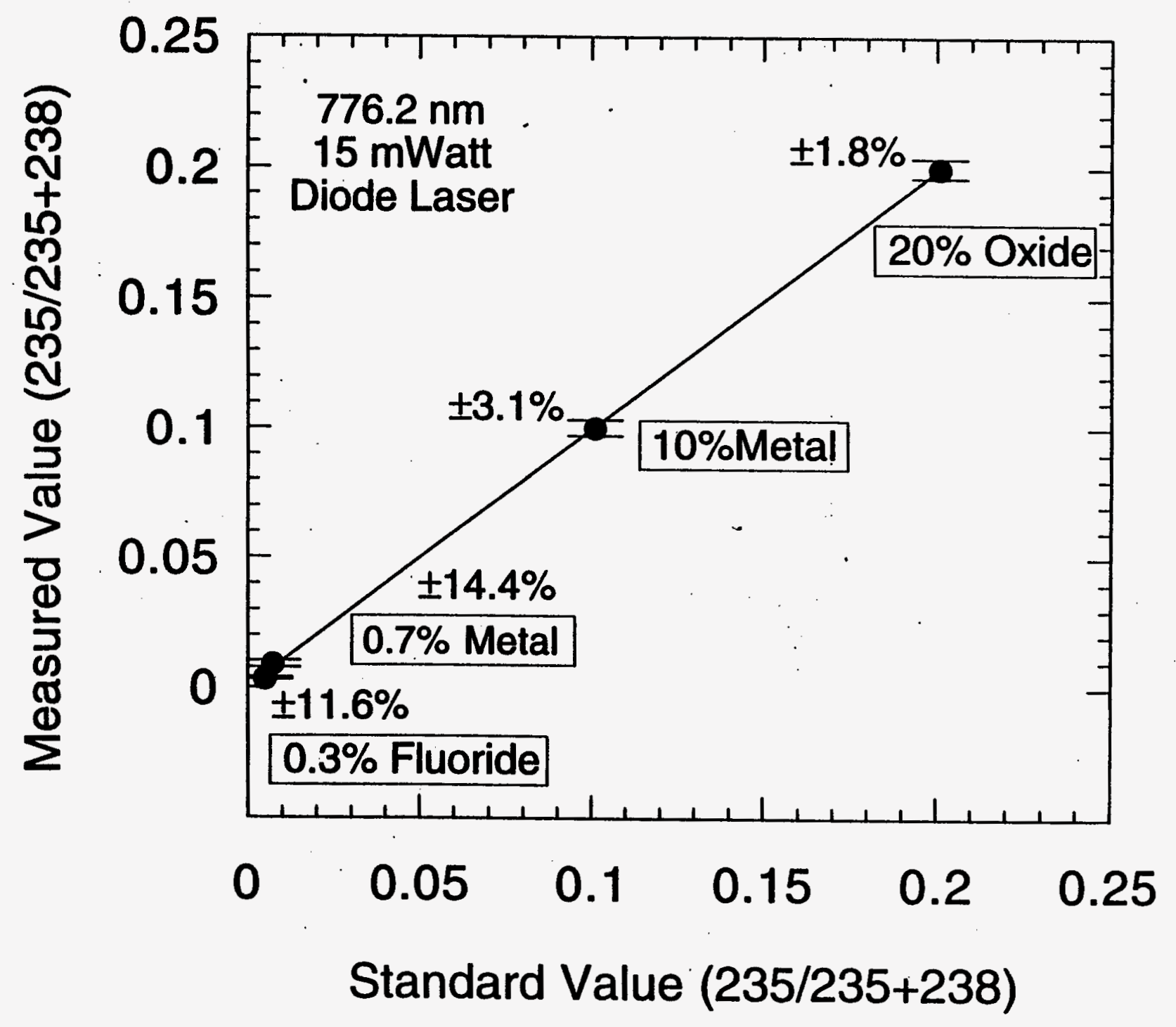




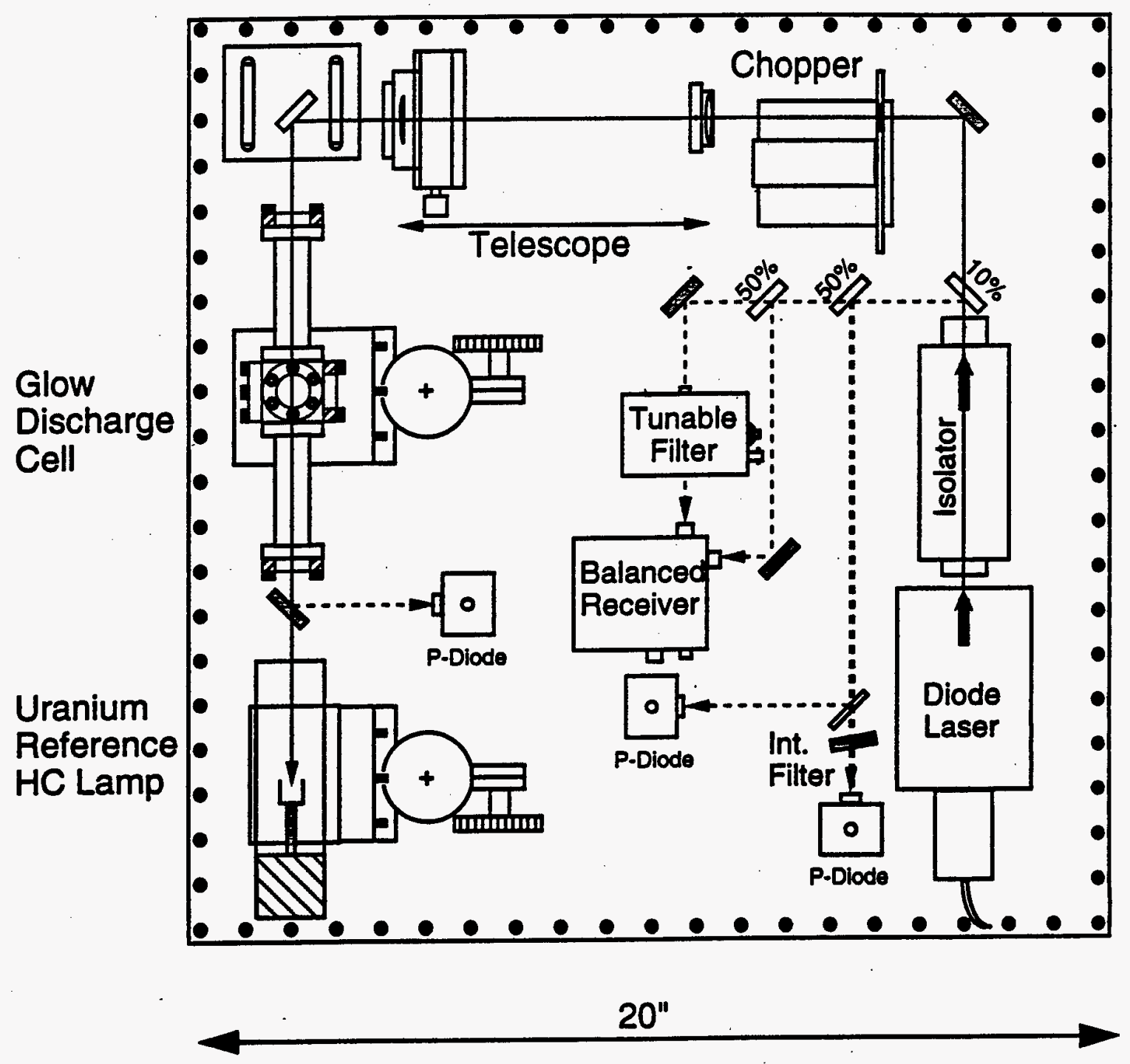




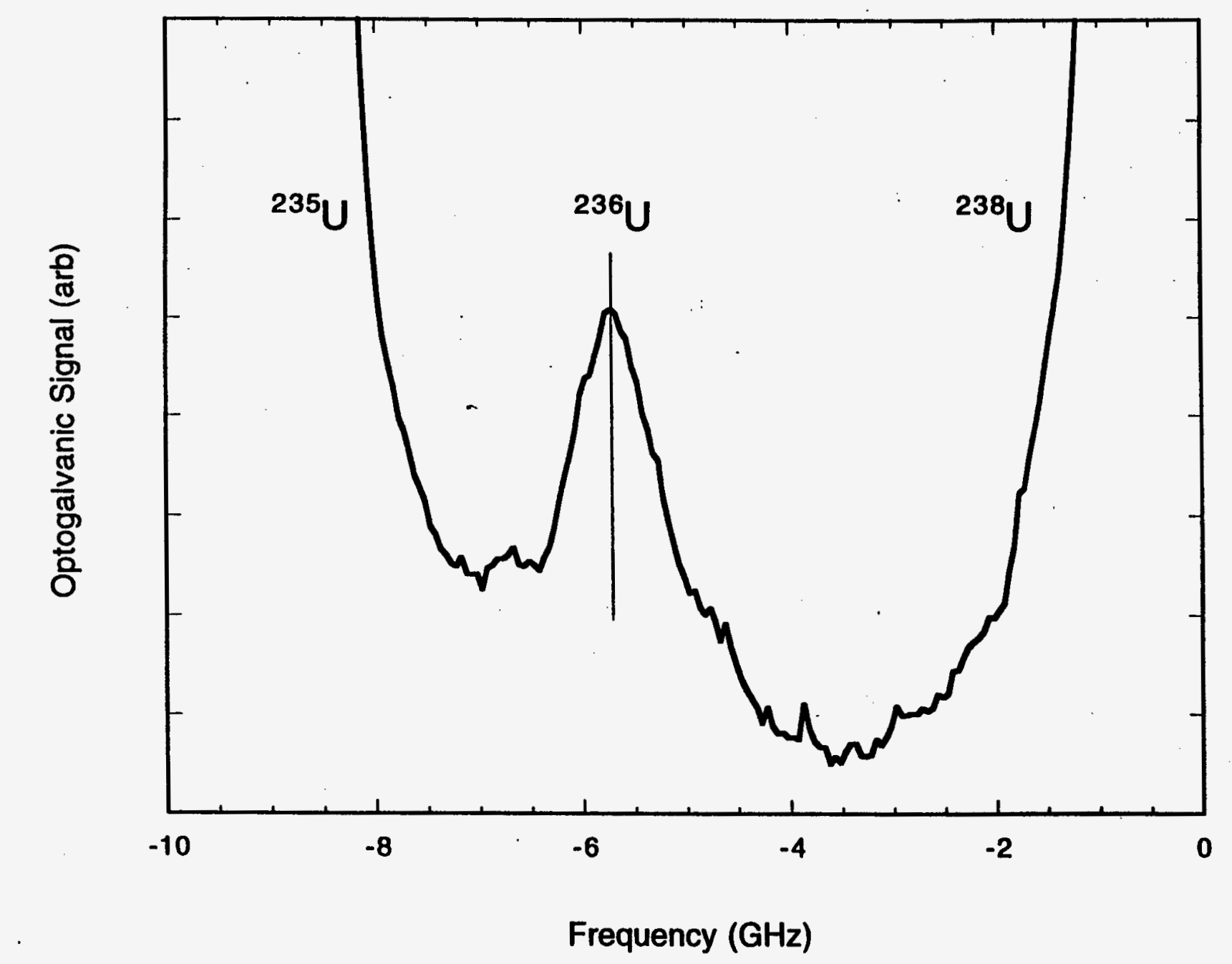




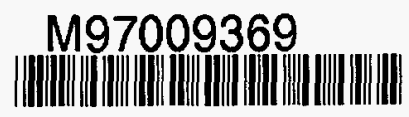

Report Number (14) CONF-970907--1

Publ. Date (11)

Sponsor code (18) DOE/ER, XF

UC Category (19) $U C-400$, DOE $/ E R$ 